\title{
Intrahepatic cholestasis of pregnancy: maternal and fetal outcome and its correlation with serum bile acid levels
}

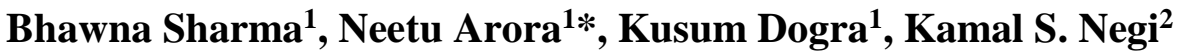

\begin{abstract}
${ }^{1}$ Department of Obstetrics and Gynecology, ${ }^{2}$ Department of Community Medicine, Shri Guru Ram Rai Institute of Medical and Health Sciences, Dehradun, Uttarakhand, India
\end{abstract}

Received: 10 October 2018

Accepted: 19 October 2018

\section{*Correspondence:}

Dr. Neetu Arora,

E-mail: rometraneetu@gmail.com

Copyright: (c) the author(s), publisher and licensee Medip Academy. This is an open-access article distributed under the terms of the Creative Commons Attribution Non-Commercial License, which permits unrestricted non-commercial use, distribution, and reproduction in any medium, provided the original work is properly cited.

\begin{abstract}
Background: Maternal, fetal, and neonatal outcomes in parturients with intrahepatic cholestasis of pregnancy (ICP) have been retrospectively documented. We aimed to present pregnancy outcomes of parturients with ICP who underwent delivery. The study was conducted during a 1-year period in a tertiary care centre.

Methods: Data from 1 January to 31 December 2017 were collected to identify parturients with ICP.

Results: Almost 3/4th of births came to a vaginal delivery (76.74\%) and only 10 parturients had cesarean delivery. 4 of 10 parturients underwent nonelective cesarean section, while 6 had elective cesarean delivery. $15.15 \%$ vaginal deliveries were instrumental. The most common indications for emergency LSCS and instrumental deliveries was fetal distress followed by failure to progress of labour. Most births occurred at or after 37 weeks of gestation (65\%). Regarding neonatal outcomes in terms of birth weight and Apgar scores at 1 and 5 min, they were positive, as well. None of the babies had Apgar score $<7$ at 5 minutes. No case of perinatal death was observed.

Conclusions: Although the results were generally positive, larger studies need to be conducted to evaluate the maternal and fetal outcomes in ICP and correlation with serum bile acid levels.
\end{abstract}

Keywords: Fetal outcome, Intrahepatic cholestasis of pregnancy, ICP, Maternal

\section{INTRODUCTION}

Certain liver diseases that are uniquely associated with pregnancy include hyperemesis gravidarum, acute fatty liver of pregnancy, intrahepatic cholestasis of pregnancy (ICP), and HELLP (hemolysis, elevated liver enzymes, low platelets) syndrome. Among these, ICP is the commonest liver related disorder. ${ }^{1}$ It generally occurs in the second or third trimester with a mean onset at 30 weeks' gestation, and it occurs approximately 1 to 2 times per 1000 pregnancies. Generalized peripheral pruritus is commonly the first sign of the disease, but it is usually resolved within 48 hours of delivery. Approximately $10 \%$ to $25 \%$ of patients develop jaundice, while some patients may occasionally suffer from chills and abdominal pain. Some may also develop diarrhoea or steatorrhea. The differential diagnosis includes viral or autoimmune hepatitis, primary biliary cirrhosis, and cholelithiasis. $^{2-5}$ The pathogenesis of ICP remains poorly understood: inflammatory, immunological and genetic influences contribute, as does pre-existing hepatobiliary disease. ${ }^{6-8}$

ICP may be a challenge for health care providers because of the potential of severe fetal consequences, including prematurity and stillbirth. For the women, there are risks of recurrence and also of future hepatobiliary, cardiovascular and immunological diseases. ${ }^{9-10}$ Generally serious outcomes have been associated with BA $>40$ $\mu \mathrm{mol} / \mathrm{L}$. 
Early obstetric management of the disease is essential when diagnosed by measuring the high levels of bile acid levels in the serum. Therefore, we aimed to document maternal and pregnancy outcomes of parturients with ICP who underwent delivery during a 1-year period in present unit and compare the results between mild and severe disease.

\section{METHODS}

A retrospective study was conducted in the Obstetrics and Gynaecology Department of a tertiary care hospital, with data collected from $1^{\text {st }}$ January to $31^{\text {st }}$ December 2017.

\section{Inclusion criteria}

- Patients with singleton pregnancy with symptoms of pruritus and serum bile acid levels $\geq 10 \mu \mathrm{mol} / \mathrm{L}$.

\section{Exclusion criteria}

- $\quad$ Patients with multiple pregnancy.

- Patients with one or more medical diseases such as cardiac, oncologic, hematologic, acute or chronic renal disease.

- Patients with other hepatobiliary disorders like hepatitis A, B, C, D and E, biliary stones, cholangitis.

The severity of ICP was classified according to fasting serum bile acid levels (bile acid levels of $\geq 10-39 \mu \mathrm{mol} / \mathrm{L}$ and $\geq 40 \mu \mathrm{mol} / \mathrm{L}$ regarded as mild and severe ICP, respectively. Results were expressed as mean \pm standard error of mean (SEM), number, or median, as appropriate. Comparisons regarding the different parameters among the two groups were performed with Fischer's test or Chi-square test as appropriate. $\mathrm{P}<0.05$ was considered as statistically significant.

\section{RESULTS}

Authors identified 43 parturients diagnosed as ICP in a 1year period. According to the level of fasting serum bile acids, the rates of mild and severe ICP were $65 \%(n=28)$ and $35 \% \quad(n=15)$, respectively. The maternal characteristics are shown in Table 1.
Table 1: Demographic characteristics.

\begin{tabular}{|ll|}
\hline Age $($ years $)$ & Mean \pm SE \\
\hline Weight $(\mathrm{kg})$ & $28.67 \pm 0.61$ \\
\hline Height $(\mathrm{cm})$ & $72.4 \pm 2.8$ \\
\hline BMI $\left(\mathrm{kg} / \mathrm{cm}^{2}\right)$ & $160.9 \pm 1.4$ \\
\hline Serum bile acid $(\mu \mathrm{mol} / \mathrm{L})$ & $27.9 \pm 0.9$ \\
\hline
\end{tabular}

Fasting serum bile acid levels, liver enzymes, and bilirubin levels are shown in Table 2. There were no significant differences between these parameters among the two groups except for the values of SGPT.

Table 2. Fasting serum bile acid levels, bilirubin levels and liver enzymes of parturients $(n=43)($ Mean \pm SD $)$.

\begin{tabular}{|lll|l|}
\hline $\begin{array}{l}\text { Bile acid } \\
(\mu \mathrm{mol} / \mathrm{L})\end{array}$ & Mild $(\mathbf{n = 2 8})$ & Severe $(\mathbf{n = 1 5})$ & $\mathrm{p}$-value \\
\hline $\begin{array}{l}\text { S. bilirubin } \\
(\mathrm{mg} / \mathrm{Dl})\end{array}$ & $0.81 \pm 0.07$ & $0.8 \pm 0.09$ & $\mathrm{NS}$ \\
\hline SGOT (U/L) & $108.9 \pm 10.22$ & $114.4 \pm 15.2$ & $\mathrm{NS}$ \\
\hline SGPT (U/L) & $107.3 \pm 9.04$ & $118.1 \pm 17.41$ & $<0.05$ \\
\hline S. ALP (U/L) & $196.21 \pm 16.23$ & $204.2 \pm 22.2$ & $\mathrm{NS}$ \\
\hline PT & $10.1 \pm 0.5$ & $10.9 \pm 0.3$ & $\mathrm{NS}$ \\
\hline APTT & $0.9 \pm 0.03$ & $1.3 \pm 0.4$ & $\mathrm{NS}$ \\
\hline
\end{tabular}

Table 3 shows the maternal outcome in the patients diagnosed with ICP. 9 patients out of 43, went into spontaneous labour before any obstetric intervention, while a large proportion of births $(79.07 \%)$ followed obstetric intervention i.e. iatrogenic deliveries. About $11.6 \%$ of total births followed preterm intervention. Despite this, almost 3/4th of births came to a vaginal delivery $(76.74 \%)$ and only 10 parturients had cesarean delivery. 4 of 10 parturients underwent nonelective cesarean section, while 6 had elective cesarean delivery. $15.15 \%$ vaginal deliveries were instrumental. The most common indications for emergency LSCS and instrumental deliveries were fetal distress followed by failure to progress of labour. Gestation age, neonatal demographics, and adverse outcomes were also documented. Most births occurred at or after 37 weeks of gestation $(65 \%)$.

Table 3: Maternal outcome according to severity of ICP.

\begin{tabular}{|llll|}
\hline & Mild $(\mathbf{n = 2 8})$ & Severe $(\mathbf{n = 1 5})$ & p-value \\
\hline Total vaginal deliveries & 21 & 12 & NS \\
\hline Instrumental deliveries & 4 & 1 & NS \\
\hline Total caesarian deliveries & 7 & 3 & NS \\
\hline Elective LSCS & 5 & 1 & NS \\
\hline Emergency LSCS & 2 & 2 & $<0.05$ \\
\hline Iatrogenic preterm births & 1 & 4 & NS \\
\hline Spontaneous preterm labour & 3 & 2 & $=0.05$ \\
\hline GA at delivery (in days) Mean \pm SEM & $38.63 \pm 0.109$ & $37.08 \pm 0.107$ & \\
\hline
\end{tabular}


Table 4: Perinatal outcome according to severity of ICP.

\begin{tabular}{|llll|}
\hline & Mild $(\mathrm{n}=\mathbf{2 8})$ & Severe $(\mathbf{n}=\mathbf{1 5})$ & $\mathrm{p}$-value \\
\hline Meconium stained liquour, $\mathrm{n}(\%)$ & 1 & 1 & $\mathrm{NS}$ \\
\hline Abnormal intrapartum FHS pattern, $\mathrm{n}(\%)$ & 3 & 1 & $\mathrm{NS}$ \\
\hline Birthweight, in grams (mean \pm SE) & $2846.9 \pm 95.76$ & $2740.5 \pm 133.6$ & $\mathrm{NS}$ \\
\hline 1-minute Apgar (median) & 8 & 8 & $\mathrm{NS}$ \\
\hline 5-minute Apgar (median) & 9 & 9 & NS \\
\hline Still birth & - & - & \\
\hline
\end{tabular}

Perinatal outcomes are presented in Table 4. Regarding neonatal outcomes in terms of birth weight and Apgar scores at 1 and $5 \mathrm{~min}$, they were positive, as well. None of the babies had Apgar score $<7$ at 5 minutes. No case of perinatal death was observed.

\section{Outcomes in mild versus severe ICP}

$65.11 \%$ of the parturients were diagnosed with mild ICP. When comparing maternal characteristics, only difference found between the mild and severe cases was an earlier gestational age at delivery in the severe group and particularly an increase in the iatrogenic preterm deliveries. Birth weights, Apgar scores, and incidence of fetal distress and meconium stained liquor were comparable among mild and severe ICP cases, as shown in Table 4.

\section{DISCUSSION}

Authors retrospectively documented maternal and fetalneonatal outcomes in parturients with ICP delivered at tertiary level hospital in the present study. Maternal outcomes were generally positive, as indicated in many previous reports. ${ }^{2-5} 76.7 \%$ of patients had vaginal deliveries while the rest $(23.3 \%)$ underwent cesarean delivery.

Approximately $40 \%$ of cesarean deliveries were emergent. Similar to Brouwers et al.'s study, we documented a much higher rate of vaginal deliveries $(76.7 \%)$ as compared to caesarian deliveries. ${ }^{11}$ The present results were contradictory to those of DeLeon et al.'s study with cesarean section rate of $65 \% .^{12}$

The severity of ICP, especially in cases of bile acid levels exceeding $40 \mu \mathrm{mol} / \mathrm{L}$, may affect pregnancy outcomes. ${ }^{6,9}$ Based on these studies, we similarly classified cases with a bile acid level of $\geq 10-39 \mu \mathrm{mol} / \mathrm{L}$ and $\geq 40 \mu \mathrm{mol} / \mathrm{L}$, as mild and severe ICP, respectively although a number of previous studies classified cases into three categories, mild, moderate and severe with BA levels of 10-39, 4099 and $>/ 100 \mu \mathrm{mol} / \mathrm{L}$. In the present study, the rates of mild and severe ICP were $65.11 \%$, and $34.89 \%$ respectively

When comparing maternal characteristics, only difference found between the mild and severe cases was an earlier gestational age at delivery in the severe group and particularly an increase in the iatrogenic preterm deliveries. This was in accordance with the Browers study wherein a total of 215 women were included and Gestational age at diagnosis and gestational age at delivery were significantly lower in the severe, as compared with the mild, ICP group $(\mathrm{P}<0.001) .{ }^{11}$

Birth weights, Apgar scores, and incidence of fetal distress and meconium stained liquor were comparable among mild and severe ICP cases. This is in contrast to the study of Garcia FJ et al, where patients presenting with severe ICP (maximum bile acids levels above 40 $\mu \mathrm{mol} / \mathrm{l}$ ) showed a higher rate of meconium-stained amniotic fluid, NICU admission and neonatal global morbidity.

Present results were also contrary to those of Glantz A et al who conducted a meta-analysis and found that maternal elevated bile acid levels are significantly associated with increased risks of overall adverse perinatal outcomes, PTB, MSAF, and asphyxia or RDS. ${ }^{13,14}$ The earlier gestational age at delivery, particularly an increase in the number of iatrogenic preterm deliveries could be explained by the fact that patients were managed actively during pregnancy after an established diagnosis of ICP.

The absence of any adverse perinatal event, especially the Apgar score less than 7 at 5 minutes and still birth can also be explained by the active management and the early intervention in patients diagnosed with ICP, but it is also possible that the study was not large enough to have seen the severe neonatal asphyxia.

Despite the limitation of one-year documentation, the present small retrospective study, might be helpful for obstetricians in order to provide better management of parturients with ICP for delivery.

\section{CONCLUSION}

Although maternal and perinatal outcomes were generally positive and no significant differences were found between the mild and severe groups except for the earlier gestational age at delivery large scale prospective studies need to be conducted to better evaluate the correlation of serum bile acid levels with the maternal and perinatal 
outcomes and uniform criteria need to be defined as to how these pregnancies be monitored and when the timely intervention be done to improve the maternal and fetal outcome.

Funding: No funding sources Conflict of interest: None declared

Ethical approval: Not required

\section{REFERENCES}

1. Dixon PH, Williamson C. The pathophysiology of intahepatic cholestasis of pregnancy. Clin Res Hepatol Gastroenterol 2016;40(2):141-53.

2. Kamimura K, Abe H, Kawai H, Kamimura H, Kobayashi Y, Nomoto $\mathrm{M}$, et al. Advances in understanding and treating liver disease during pregnancy. World J Gastroenterol. 2015; 21(17):5183-90

3. Ahmed KT, Almashhrawi AA, Rahman RN, Hammoud GM, Ibdah JA. Liver diseases in pregnancy: Diseases unique to pregnancy. World $\mathbf{J}$ Gastroenterol. 2013;19(43):7639-46.

4. Goel A, Jamwal KD, Ramachandran A, Balasubramanian KA, Eapen CE. Pregnancy-related liver disorders. J Clin Exp Hepatol, 2014;4(2):15162.

5. Bacq Y. Liver diseases unique to pregnancy: a 2010 update. Clin Res Hepatol Gastroenterol 2011;36(3): 182-93.

6. Biberoglu E, Kirbas A, Daglar K, Kara O, Karabulut E, Yakut $\mathrm{HI}$ et al Role of inflammation in intrahepatic cholestasis of pregnancy. J Obstet Gynaecol Res. 2016;42(3):252-7.

7. Larson SP, Kovilam O, Agrawal DK. Immunological basis in the pathogenesis of intrahepatic cholestasis of pregnancy. Expert Rev Clin Immunol. 2016;12(1):39-48.

8. Turunen K, Helander K, Mattila $\mathrm{Kj}$, Sumanen $\mathrm{M}$. Intrahepatic cholestasis of pregnancy is common among patients' first-degree relatives. Acta Obstet Gynecol Scand. 2013;92(9):1108-10.

9. Marschall HU1, Wikström Shemer E, Ludvigsson JF, Stephansson O. Intrahepatic cholestasis of pregnancy and associated hepatobiliary disease: a population-based cohort study. Hepatology 2013;58(4):1385-91.

10. Wikström Shemer EA, Stephansson O, Thuresson M, Thorsell M, Ludvigsson JF, Marschall HU. Intrahepatic cholestasis of pregnancy and cancer, immune-mediated and cardiovascular diseases: A population-based cohort study. J Hepatol. 2015;63(2):456-61.

11. Brouwers L, Koster MP, Page-Christiaens GC, Kemperman H, Boon J, Evers IM et al. Intrahepatic cholestasis of pregnancy: maternal and fetal outcomes associated with elevated bile acid levels. Am J Obstet Gynecol. 2015;212(1):100.e1-7.

12. DeLeon A, De Oliveira GS, Kalayil M, Narang S, McCarthy RJ, Wong CA. The incidence of coagulopathy in pregnant patients with ICP: should we delay or avoid neuraxial anaesthesia? J Clin Anesth 2014;26(8):623-7.

13. Garcia-Flores J1, Cañamares M, Cruceyra M, Garicano A, Espada M, Lopez A et al. Clinical value of maternal bile Acid quantification in intrahepatic cholestasis of pregnancy as an adverse perinatal outcome predictor. Gynecol Obstet Invest. 2015;79(4):222-8.

14. Glantz A, Marschall HU, Mattsson LA. Intrahepatic cholestasisof pregnancy: relationship between bile acid levels and fetal complication rates. Hepatology 2004;40(2):467-74.

Cite this article as: Sharma B, Arora N, Dogra K, Negi KS. Intrahepatic cholestasis of pregnancy: maternal and fetal outcome and its correlation with serum bile acid levels. Int $\mathbf{J}$ Reprod Contracept Obstet Gynecol 2018;7:4403-6. 